\title{
Experiência extensionista universitária no assentamento de reforma agrária Mandacaru: perspectivas, desafios e aprendizado
}

\author{
Lucia Marisy Souza Ribeiro de Oliveira ${ }^{1}$
}

\begin{abstract}
RESUMO: $O$ objetivo dessa experiência extensionista realizada no Assentamento Mandacaru foi formar Agentes de Desenvolvimento Sustentável para atuarem na comunidade, na perspectiva da produção agropecuária para a geração de trabalho, renda e minimização da pobreza. Para tanto, a UNIVASF - Universidade Federal do Vale do São Francisco se propôs a identificar as necessidades da população e, com ela, eleger ações capazes de lhe dar empoderamento. Foi uma atividade de intervivência, caracterizada pela troca de saberes entre a academia $e$ os assentados, com a finalidade de proporcionar aos alunos vivências práticas em meio real.
\end{abstract}

Palavras- chave: reforma agrária, desenvolvimento sustentável, extensão universitária

Área Temática: Extensão universitária.

1 Professora da Universidade Federal do Vale do São Francisco - luciamarisy@uol.com.br. 


\section{Extensionist university experience in the rural settlement of land reform at Mandacaru: perspectives, challenges and learning}

ABSTRACT: This work was done with farmers in the Mandacaru Land Reform Settlement located in the town of Petrolina, State of Pernambuco, in order to serve as Agents of Sustainable Development. It has been proposed to identify their needs and choose the actions to give them empowerment for being subject of their own story. It was an activity based on exchange of knowledge between UNIVASF and community, whicht has been achieved through the Thematic Nucleus "Environment and Sustainable Development", within the purpose of generating jobs and income.

Keywords: land reform, sustainable development, college inter-living.

Thematic area: college inter-living

\section{Experiencia universitaria extensionista en el asentamien- to de reforma agraria Mandacaru: perspectivas, desafíos y aprendizajes}

RESUMEN: Capacitar a los agricultores en el Asentamiento de la Reforma Agraria Mandacaru Terreno ubicado en la ciudad de Petrolina, Estado de Pernambuco, con el fin de servir como agentes del desarrollo sostenible. Por lo tanto, se ha propuesto la identificación de sus necesidades $y$, junto con ellos, elegir acciones capaces empoderarlos a fin de que sean los sujetos de su propia historia. La intervivencia con la UNIVASF se ha logrado a través del núcleo temático "Medio Ambiente y Desarrollo Sostenible", dentro del propósito de generar empleo se ingresos.

Palabras claves: reforma agraria, desarrollo sostenible, intervivencia universitaria.

Área temática: iIntervivencia universitaria 


\section{INTRODUÇÃO}

A UNIVASF - Universidade Federal do Vale do São Francisco foi criada em 2004, com o propósito de oferecer ensino superior de qualidade a todo o semiárido nordestino. Sua sede é na cidade de Petrolina - PE, possuindo campus em Juazeiro e Senhor do Bonfim, no estado da Bahia e em São Raimundo Nonato, no estado do Piauí. $\mathrm{Na}$ sua composição curricular, aparece como elemento obrigatório para os alunos cursarem Núcleo Temático Interdisciplinar, cujo objetivo é a ampliação do conceito de educação, não ficando ele restrito na universidade ao interior de cada curso, podendo ser transposto para os espaços do trabalho; do associativismo; do cooperativismo; dos assentamentos de reforma agrária; dos movimentos sociais; dos sindicatos; das colônias de pescadores e outros, por ser hoje vital que a diversidade histórico-cultural e o reconhecimento do outro, sejam metas na formação dos sujeitos enquanto cidadãos.

O Núcleo Temático Meio Ambiente e Desenvolvimento Sustentável que abrigou a experiência aqui relatada, foi criado no ano de 2006 com a proposta de estabelecer conexão entre os saberes da academia e os saberes populares outrora marginalizados, subvertendo as convenções antes estabelecidas. A compreensão de desenvolvimento sustentável que o norteia está assentada em teóricos como Zapata (2000:18), para quem o desenvolvimento local sustentável pressupõe um novo paradigma de desenvolvimento humano que se orienta por resultados em quatro dimensões: econômica - capacidade de usar e articular fatores produtivos endógenos para gerar oportunidades de trabalho e renda, fortalecendo as cadeias produtivas locais e integrando redes de pequenas empresas; sociocultural - maior participação do cidadão nas estruturas de poder, tendo como referência a história, os valores e a cultura do território; político-institucional - construção de políticas territoriais negociadas entre agentes governamentais, do mercado e da sociedade civil para as transformações da sociedade e ambiental - compreensão do meio ambiente a partir do princípio da sustentabilidade em qualquer opção transformadora.

Foi nessa perspectiva que o Núcleo atuou no assentamento Mandacaru, buscando o desenvolvimento através de um conjunto de ações interdependentes que se articulassem e reforçassem mutuamente, de forma que o capital humano influísse no capital social, ampliando a participação e transformação, com respeito ao meio ambiente.

A ampliação do acesso à informação e ao conhecimento através de processos contínuos de capacitação promove mudanças de comportamento, transformando as pessoas em agentes produtivos, 
atores sociais da sua existência. Além da dimensão humana, a dimensão social passou a ser amplamente incorporada ao conceito de desenvolvimento, a partir dos estudos de Putnam (1996:29), cujo entendimento sobre desenvolvimento tem por base a formação do capital social. Para esse autor, quanto maior a capacidade de as pessoas se associarem em torno de valores e interesses comuns, de construir acordos, redes, sinergias, de desenvolverem relações de confiança e de cooperação entre si e com outros grupos, melhores as condições de desenvolvimento, razão pela qual na experiência aqui relatada, atuou-se fortemente na organização comunitária e na participação coletiva dos agentes populares, com o objetivo de desenvolver o protagonismo local, permitindo:

- Identificar potencialidades, oportunidades, vantagens comparativas e competitivas, problemas, limites e obstáculos ao seu desenvolvimento.

- Escolher vocações, estabelecer metas, definir estratégias e prioridades, monitorar e avaliar resultados.

- Capacitar para planejar e gerenciar, de forma compartilhada, o processo de desenvolvimento.

A opção pela experiência em assentamento de Reforma Agrária deveu-se à constatação de que a globalização constituiu-se nas últimas décadas em um dos principais mecanismos de produção de desigualdades, cabendo à universidade abrir caminho para um projeto mais solidário de sociedade que inclua os "subcidadãos" que sobrevivem em condições de extrema precariedade, estando aí os trabalhadores do campo; mas principalmente pela possibilidade de permitir aos alunos uma imersão na realidade social.

\section{Caracterização do assentamento Mandacaru}

Localizado nas cercanias do Projeto de Irrigação Senador Nilo de Souza Coelho, distante aproximadamente $15 \mathrm{Km}$ do centro de Petrolina - PE, o Assentamento de Reforma Agrária Mandacaru possui setenta famílias e aproximadamente trezentas pessoas, oriundas dos municípios de Floresta, Cabrobó, Orocó, em Pernambuco, e de algumas cidades do Rio Grande do Norte e do Ceará. Muitos desempregados da área urbana de Petrolina também viram no projeto de reforma agrária a chance de possuir moradia e terra para plantar e dela sobreviver, mesmo sem ter qualquer afinidade com a atividade agropecuária.

Os adultos possuíam, à época, idades entre 35 e 60 anos e a escolaridade de $25 \%$ não ultrapassava quatro anos de estudo, sendo $75 \%$ de analfabetos e apenas uma assentada com curso de nível médio completo em agropecuária, o que a diferenciava dos demais. 
Antes de se assentarem, essas pessoas passaram três anos acampados embaixo das lonas, momento importante para se conhecerem e aprofundarem o sentimento de pertencimento à terra como bem social para a geração de trabalho e renda. Nenhum, à época da atividade, possuía renda fixa, pois a principal fonte de renda era o trabalho nas fazendas como diarista sem garantias trabalhistas, não ultrapassando um salário mínimo.Entretanto, dado o caráter sazonal da produção, menos de $30 \%$ conseguiam tal rendimento, o que caracterizava aquela população como muito pobre.

No assentamento não havia escola, posto de saúde, nem serviço de abastecimento regular de água para consumo humano e animal, sendo o mesmo feito por meio de carro pipa, às vezes fornecido pela Prefeitura, às vezes comprado pelos próprios usuários. As crianças se deslocavam até o Núcleo Habitacional do Projeto Senador Nilo Coelho para frequentarem as aulas, correndo riscos no trajeto de serem atropeladas, já que o fluxo na rodovia é intenso. Para atendimento médico, os doentes se dirigiam até o centro de Petrolina por vários dias até conseguirem uma ficha para consulta.

Cada assentado recebeu do INCRA um lote de 3,8 hectares, com a explicação de que ali seria um projeto irrigado. A partir dessa informação, a expectativa dos assentados era cultivar uva e manga, a exemplo dos seus vizinhos, grandes produtores dessas culturas para exportação. Portanto, o sonho da riqueza sempre esteve presente nos seus imaginários. Fazer pequenos cultivos e criar pequenos animais até então, estava fora das suas expectativas de vida e de trabalho.

Havia uma associação dos assentados criada para ajudá-los na defesa dos seus interesses e para buscar recursos para a produção, mas o nível de organização da população era muito incipiente. Nas reuniões provocadas por ela, poucos compareciam e a descrença na organização se evidenciava nos discursos dos associados. As mulheres tinham pouca participação e apenas uma ocupava cargo na diretoria. Os jovens não se articulavam e permaneciam à margem das discussões e deliberações.

\section{A história}

A escolha desse espaço para a experiência deveu-se às denúncias do Sindicato dos Trabalhadores na Agricultura feitas através da mídia local sobre a situação da reforma agrária no município, apontando a penúria a que estavam submetidos os assentados de reforma agrária. Lá chegando, a preocupação imediata dos docentes e discentes envolvidos com o projeto foi tentar compreender a trajetória percorrida pela população, os seus (des) caminhos, as suas dificuldades e os seus ganhos, a fim de que o planejamento coletivo 
das atividades fosse desenhado. Respostas às seguintes indagações eram necessárias: Por que as mulheres e os homens ali assentados após a luta pela terra, continuavam depois de oito anos sendo mão de obra alugada nas fazendas da circunvizinhança? Por que não se tornaram agricultores e agricultoras, já que eram beneficiários da reforma agrária? Quais os apoios recebidos do Estado? Quais as suas expectativas para o futuro e o que esperavam da UNIVASF?

A fim de iniciar o planejamento coletivo, foram feitas consultas a profissionais e solicitados documentos aos órgãos públicos: Instituto Nacional de Crédito e Reforma Agrária (INCRA), Companhia de Desenvolvimento do Vale do São Francisco (CODEVASF) e Empresa Brasileira de Pesquisa Agropecuária (EMBRAPA), de forma a comparar as informações dos assentados e aquelas existentes nessas instituições. O INCRA, por ser responsável pela Reforma Agrária, foi o primeiro a ser consultado e negou qualquer possibilidade de irrigar as terras do assentamento. Deste órgão foram solicitados os documentos memoriais para a compreensão de como, em área de sequeiro, os assentados puderam ter recebido lotes tão pequenos, absolutamente incompatíveis com atividades agropastoris possíveis de ali serem realizadas. Os documentos não foram fornecidos sob a alegação de quando da realização da operação, os técnicos do escritório eram outros. Apesar de reconhecerem a ilegalidade em relação ao tamanho dos módulos, já que no Estado de Pernambuco, para a área de sequeiro, este valor é em torno de 60 hectares no mínimo, os técnicos recusaram o diálogo.

A CODEVASF foi consultada devido ao fato das terras distribuídas no Assentamento Mandacaru ficarem nas cercanias do projeto de irrigação por ela administrado. O mapa pedológico da área foi localizado, e foi averiguado que a área em questão havia pertencido à MAPEL, empresa produtora de manga para exportação. $\mathrm{O}$ Governo Federal desapropriou terras dessa área para distribuição aos assentados. A surpresa é que, da área da MAPEL, esta mancha era a única inadequada para irrigação, razão pela qual foi negociada pelos proprietários. Ali, os solos se apresentavam pobres, arenosos, rasos, pedregosos, inadequados para agricultura e os lotes muito pequenos para a caprinocultura extensiva, que é uma tradição na região.

Da EMBRAPA Semiárido foi solicitada análise dos solos da área, que confirmou os dados informados pela CODEVASF. De posse dessas informações, foi marcada uma assembleia pela UNIVASF com todos os assentados, a fim de que os resultados dos contatos fossem com eles socializados.

Foi um evento grande, com $100 \%$ dos assentados presentes, 
além dos alunos e professores que compunham a equipe executora do projeto. Após as explicações, a reação de todos os assentados foi de indignação e inconformismo com os informantes. Nas suas compreensões, tudo aquilo era fruto do preconceito da universidade com eles por serem oriundos do Movimento dos Trabalhadores Sem-Terra (MST) e perguntavam: "Como pode no meio de todas essas terras onde tudo é irrigado, só a nossa terra ser imprópria para irrigação? (...) Não pensem que vamos desistir do nosso sonho. Vivemos até agora por ele e vamos conseguir o que queremos. Ninguém vai matar anos de desejo da comunidade".

Foi uma reunião tensa e de muita perplexidade. Após a explicitação de todos os desabafos, esclareceu-se para os presentes que trabalhar com a UNIVASF era uma opção que a comunidade poderia concretizar ou descartar, a depender do nível de confiança existente entre as partes. Entretanto, foi proposta a realização de um seminário onde alternativas de produção pudessem ser conhecidas e analisadas pelo coletivo, tendo sido a proposta acatada.

O Seminário foi realizado na UNIVASF no dia 05 de maio de 2008, durante um dia inteiro. Técnicos de várias áreas apresentaram alternativas de produção, considerando a pouca terra e as suas possibilidades de solo e de água. Um novo exame pedológico demonstrou a presença de uma mancha de 30 hectares possível de ser irrigada, e que, pela proximidade com o canal de irrigação da CODEVASF, foi obtida a autorização para irrigá-la usando água a custo zero, sob a condição de que o plantio fosse coletivo, ficando 0,5 hectare para cada família.

Além dessa possibilidade, grupos foram formados para trabalhar na criação de galinha caipira, de caprino em sistema de confinamento, e no cultivo de uma horta agroecológica, cujos canteiros passaram a ser irrigados manualmente com água do canal.

Para o início das atividades, capacitações foram feitas em gestão participativa; desenvolvimento comunitário; cooperativismo/ associativismo; empreendedorismo; gestão de conflitos; mutirão; economia solidária; administração da produção; gestão financeira; manejo de culturas dependentes de pouca água, além de visitas técnicas em locais diversos, como mecanismos de aprendizagem.

Essas ações viabilizaram a interação universidade/sociedade, promovendo a troca de saberes entre os seus atores e reafirmando a crença de que a extensão universitária é processo educativo que, ao abordar a realidade na sua plenitude, promove a produção do conhecimento de forma integrada. As ações possibilitaram ainda a interdisciplinaridade entre as áreas como parte da construção do 
conhecimento, em oposição à formação na universidade, que tem como característica hegemônica a fragmentação do conhecimento, onde os currículos são constituídos por compartimentos estanques e incomunicáveis, que produzem uma formação humana e profissional de alunos e professores insuficiente para o enfrentamento das práticas sociais que exigem formação mais crítica e competente (MANACORDA, 1991:8; ALMEIDA FILHO, 1997:37).

A integração teoria e prática de que trata a interdisciplinaridade refere-se à formação na perspectiva da totalidade. Ao capacitar os assentados, os alunos e os professores também aprenderam com as suas ações e reações. Dessa forma, a prática exigiu a reflexão teórica, a superação da ação não pensada pela prática concreta, refletida, a ação concreta pensada (SAVIANI, 1991:44), o que significa dizer que a interdisciplinaridade é mais do que a compatibilização de métodos e técnicas de ensino. É, como defende Frigotto(1995:16), uma necessidade e um problema relacionado à realidade concreta, histórica e cultural, constituindo-se assim como um problema ético, político, econômico, cultural e epistemológico.

Trazendo essas reflexões para a compreensão do tema aqui abordado, a interdisciplinaridade pode ser tomada como uma possibilidade de quebrar a rigidez dos compartimentos em que se encontram isoladas as disciplinas dos currículos dos vários cursos, desenhando um recorte mais amplo para a construção do conhecimento, o que só foi possível na UNIVASF- uma instituição muito jovem criada no ano de 2004 - pela existência do Núcleo Temático, que apesar de ser componente curricular obrigatório, até então, não tinha sido objeto de reflexão por nenhum colegiado.

$\mathrm{Na}$ instituição, o ensino continua sendo a prioridade e a pesquisa desponta como atividade relevante. A extensão à época era invisível como atividade acadêmica; era algo de menor importância, daí a necessidade de se desencadear ações impactantes na sociedade, valorizando esse segmento que compõe um dos pilares da universidade. Nessa perspectiva, o Núcleo Temático se apresentava ideal porque a concepção de currículo que o embasa inclui no seu bojo questões da atualidade e práticas de significação pessoal para os aprendizes, onde as informações tanto podem se referir ao aperfeiçoamento da sua atividade produtiva, como ao conjunto de representações que eles têm da sociedade e das relações que mantêm com outros grupos sociais, influenciando a formação de identidades e a consolidação de valores éticos. A fim de que pudesse dar conta dos objetivos propostos, a organização do Núcleo fundamentou-se nos seguintes pressupostos: a) No âmbito ético-político, como um mecanismo comprometido com a liberdade e a autonomia compre- 
endidas como valores centrais, que se expressam no compromisso com a emancipação e a expansão dos sujeitos sociais envolvidos, assegurando a universalidade do acesso aos bens e serviços por ele disponibilizados; b) No âmbito da prática profissional, esses valores se expressam na defesa da qualidade dos serviços, na competência profissional, na viabilização dos direitos sociais e de cidadania e no aprimoramento intelectual e psicomotor dos aprendizes; por isso, a preocupação e ênfase em uma formação acadêmica sólida para os estudantes e a produção de um discurso onde a comunidade se reconheça na história e no destino partilhado, reconstruindo dessa forma o tecido social para a criação de espaços de convívio que facilitem o enfrentamento da realidade; c) No âmbito curricular, uma visão orgânica do conhecimento, afinada com as mutações que o acesso à informação está causando no modo de abordar, analisar, explicar e prever a realidade; d) No âmbito pedagógico, abertura e sensibilidade para identificar as relações que existem entre os conteúdos do ensino e das situações de aprendizagem com os muitos contextos da vida social e pessoal, de modo a estabelecer uma relação ativa entre o aprendiz e o objeto do conhecimento e a desenvolver a capacidade de relacionar o aprendizado com o observado, a teoria com suas consequências e aplicações práticas.

\section{Formação de formadores: universitários se capacitando para capacitarem outros atores sociais}

A mundialização do capital está alterando as formas de produção, exigindo trabalhadores mais versáteis, capazes de compreender processos, dotados de autonomia e iniciativa para resolver problemas em equipe. De outro lado, o avanço tecnológico tem reduzido os postos de trabalho, obrigando a muitos a inserção no mercado de trabalho pelo empreendedorismo, organização de microempresas ou atuação no mercado informal. Essas formas alternativas que se apresentam, também exigem autonomia, capacidade de iniciativa, de comunicação e reciclagem constante do trabalhador; portanto, pode-se afirmar sem muitos rodeios, que hoje exige-se melhor formação geral do trabalhador e não apenas domínios em áreas específicas.

$\mathrm{Na}$ zona rural, os agricultores assentados da Reforma Agrária têm poucas chances de utilizar as oportunidades de aperfeiçoamento, enfrentando, assim, maiores dificuldades para se colocarem no mercado. Com pouca terra; baixa ou nenhuma escolaridade; desconhecimento das tecnologias modernas de produção; desassistência técnica; ausência de crédito subsidiado e de insumos de qualidade e, sobretudo, ausência de cidadania, produzir torna-se uma tarefa difícil, passando a educação a assumir importante papel na consolidação da democracia. 
Para se ter acesso a muitos dos benefícios da sociedade moderna, é preciso ter domínio dos instrumentos da cultura letrada: tirar documentos; chegar aos serviços públicos; cuidar da saúde; apoiar os filhos na escola; usufruir da cultura; fazer escolhas conscientes. Portanto, promover a educação de jovens e adultos que não tiveram a oportunidade de cumpri-la na infância é importante para responder aos imperativos do presente e também para garantir melhores condições educativas para as próximas gerações. Conhecimento e ação devem andar juntos porque, a teoria separada da prática perde muito do seu valor.

Baseado nessa compreensão, os universitários da UNIVASF vinculados ao Núcleo Temático, passaram a ser preparados pelos professores que aderiram ao projeto, para atuarem na educação dos assentados, a partir do conhecimento da sua realidade, a fim de agir em respeito à motivação para desenvolver suas capacidades; enriquecer os seus conhecimentos; melhorar as suas competências técnicas ou profissionais, formando pessoas para se tornarem cidadãs e cidadãos do mundo, no mundo, para a vida, o trabalho e as suas adversidades, reorientando-as para melhor atender as suas necessidades e as da sociedade. Para tanto, a metodologia partiu sempre da problematização da vida cotidiana dos aprendizes, onde os conteúdos emergiam dos seus desafios, obstáculos, necessidades e carências.

Trabalhou-se pautado na andragogia, que é o caminho metodológico que busca compreender o jovem e o adulto nos aspectos psicológico, biológico e social, na perspectiva de que a aprendizagem desses sujeitos é orientada para a resolução de problemas e tarefas com os quais se confrontam na sua vida cotidiana.

Não foi uma tarefa fácil já que, os capacitandos sempre queriam ver a aplicação imediata do que estavam aprendendo, o que requeria muito estudo dos formadores, planejamento cuidadoso tanto dos conteúdos a serem trabalhados, quanto da metodologia de abordagem, levando-se em conta o tempo e os recursos disponíveis.

Experiências passadas de fracasso e exclusão produziam nos jovens uma baixa autoestima, às vezes expressa em indiferença e desinteresse. Nos mais velhos, essa baixa autoestima se traduzia em timidez, insegurança, bloqueios e descrédito.

Para os capacitadores da UNIVASF, cuja formação em bacharelado não incluía os tratos para a docência, foi um exercício que exigiu solidariedade; disposição para encarar as dificuldades como desafios; e a presença constante no assentamento para conhecer as expectativas, a cultura, as características, as necessidades de aprendi- 
zagens e mais que tudo, o estabelecimento de relações de confiança com os assentados. Foi uma experiência ao mesmo tempo rica e de muita ansiedade para todos os envolvidos.

No processo, os alunos formadores foram estimulados a favorecer a autonomia dos assentados, sendo orientados a avaliarem constantemente os seus progressos e as suas dificuldades; e a buscarem alternativas de soluções para os seus próprios problemas, na compreensão de que aqueles jovens e adultos que ali estavam, migraram de áreas empobrecidas após experiências de trabalho duro na roça, tanto na infância quanto na adolescência, o que os impossibilitou de uma vida mais digna. Claro está que, no cotidiano vivenciado ao longo dos anos, essas pessoas acumularam conhecimentos úteis. Entretanto, continuavam excluídas de muitas possibilidades que a cultura oferece. Assim, a orientação metodológica para os alunos é que eles deveriam valorizar esse conhecimento existente, considerando as respostas dadas às seguintes indagações: Quais os pontos a serem explorados nas capacitações? O que os participantes já sabem sobre o tema? Quais as suas experiências com os assuntos?

O aprendente é sujeito ativo no processo de ensino-aprendizagem, daí a insistência para se explorar ao máximo suas próprias idéias, ampliando-as após as discussões estabelecidas. O papel questionador e problematizador exercido pelo formador; a exposição das propostas pelo grupo; os debates em plenária, após as exposições e os trabalhos em grupo, num verdadeiro vai e vem de pensamentos até chegar a uma proposta possível, compreendida e significativa para todos, foram recursos usados no intuito de fortalecer a autonomia dos participantes, aprendentes e ensinantes, construindo novas e mais complexas elaborações e sujeitos mais críticos e construtivos. Nessa metodologia, formadores e assentados se constituíam uma unicidade, onde todos aprendiam e todos ensinavam, os dois ao mesmo tempo sendo educadores e educandos, sujeitos ativos da reelaboração do conhecimento presente, possibilitando a síntese entre o que os assentados já traziam das suas experiências de vida e trabalho e os novos conhecimentos que lhes foram apresentados.

Somado a esses aspectos, é importante trazer à tona para reflexão a importância da presença da Universidade num espaço rural popular para o debate da cidadania, onde se abordou os cuidados com os bens coletivos; a participação democrática nos destinos da cidade e do campo; a responsabilidade individual para o bem comum; direitos; políticas públicas; o papel do estado; desenvolvimento comunitário e outros. 
Uma pesquisa realizada no assentamento Mandacaru para conhecimento da sua realidade, executada por alunos de iniciação científica da UNIVASF, apontou como um dos interesses da população ao aprender mais, a oportunidade de ganhar melhor, quer como assalariado, quer como produtor, mas suas motivações não se limitavam a este aspecto. Muitos referiram também à vontade mais ampla de "entender melhor as coisas", "se expressar melhor", de "ser gente", de "não depender sempre dos outros", especialmente as mulheres, pelo desejo de ajudar os filhos com os deveres escolares ou, simplesmente, de lhes dar um bom exemplo.

$\mathrm{Na}$ operacionalização da experiência, enquanto os alunos do curso de Psicologia cuidavam das questões relacionadas à organização da comunidade; das relações interpessoais e da administração de conflitos, que se apresentavam muito evidentes entre eles, os alunosdo curso de Administração de Empresas discutiam a formação e o funcionamento da Associação como mecanismo de profissionalização e empreendedorismo. Enquanto isso, alunos do curso de Engenharia Agrícola e Ambiental, Zootecnia e Medicina Veterinária, promoviam ações de Educação Ambiental e elaboração de Projetos Agropastoris para a geração de trabalho e renda. A ação dos alunos de Engenharia Civil foi no sentido de construir o Centro de Convivência no assentamento, orientando os mutirões como metodologia e os alunos do curso de Enfermagem realizavam procedimentos de saúde como prática, pela valorização da vida plena.

Alunos dos cursos das Engenharias da Produção, Elétrica e Mecânica, orientavam a instalação da fábrica de vassoura com garrafa PET, o seu processo produtivo, integrando as informações discutidas de forma interdisciplinar, unindo os saberes populares aos acadêmicos, resultando outro saber mais rico e capaz de transformar intenções em realidade; enquanto atividades de arte educação passaram a ser realizadas com os jovens, filhosdosassentados, priorizando a dança, o teatro e a música como ferramentas educativas. Além disso, foram responsabilizados pela revitalização dos espaços públicos, com plantiodeárvores doadaspelas empresas Agroindústrias do Vale do São Francisco S/A - AGROVALEe EMBRAPA Semiárido, além da articulação das festividades locais.

As mulheres mais idosas foram inseridas em oficinas de artesanato em tecido, cuja matéria- prima passou a ser doada por uma indústria fabril, a ACCOST. Com esse material, passaram a ser elaboradas colchas de retalhos, toalhas e colchas de fuxico, muito valorizadas nas feiras e eventos culturais. A venda do artesanato gerou às mulheres uma renda para assumir algumas despesas pessoais e com a manutenção da família. 
Visitas técnicas foram realizadas com o intuito de favorecer a consolidação das ações pela familiaridade adquirida na prática. Os contatos estabelecidos na Serra da Capivara com os artesãos da cerâmica; na Cooperativa dos Pequenos Agricultores dos municípios de Curaçá, Uauá e Canudos - COOPERCUC - com os agricultores familiares para o conhecimento de como ocorreu o processo de industrialização dos frutos regionais e a sua inserção na Economia Solidária; na Associação dos Pequenos Agricultores do Estado da Bahia - APAEB, no município de Valente-Bahia. As visitas foram fundamentais para os envolvidos, tanto os assentados, como os docentes e discentes, que aprenderam coletivamente, a constatar como é possível com organização vencer a pobreza.

Como afirma Kieling (2001:21), a educação deve ser pensada "como possibilidade de construir o ser a partir de situações históricas de não ser: fome, miséria, privação da cultura, do lazer, da atividade da escola, da participação na riqueza social, da exclusão das atividades consideradas construção da importante vida em sociedade". Trata-se, como na visão de Paulo Freire (2002:9), de uma educação para a libertação, onde jovens, homens e mulheres aprendem a ser sujeitos de si mesmos e da sua história.

Os depoimentos dos alunos formadores são reveladores da significação dessa atividade para eles:

"Confesso que não entendia o que alunos do curso de Engenharia Civil estavam fazendo num assentamento de reforma agrária. Quando me matriculei no Núcleo Temático, queria apenas me ver livre da exigência, mas não achava que poderia aprender algo útil para a minha vida e a minha profissão. Com o passar do tempo, fui me envolvendo e me apaixonando pelo trabalho, de forma que bastava eu ver algo que poderia ser interessante para aquela realidade, eu já ficava interessado em levar para lá. Aprendi muito e me tornei melhor como gente. Minha família possui fazenda de cacau e sempre ouvi dizer na minha região que o MST era formado por um grupo de vagabundos que não quer trabalhar, mas se apossar das terras de quem lutou para consegui-las. Hoje sei que esta é apenas uma parte da verdade. Conheci no assentamento trabalhador honesto, gente de bem"( M.S.F. Aluno de Eng.Civil).

Na primeira vez que fui ao assentamento tive medo. Nunca tinha ido num lugar tão pobre e o que eu sabia sobre os assentamentos era aquilo mostrado pela televisão. Gente de foice e pau armados para enfrentar a polícia. E pensava: essa gente das Ciências Sociais tem cada coisa...Participei da elaboração do projeto de elétrica para o Centro de Convivência e pude discutir com os assentados a melhor forma de fazer as coisas. Algo que aprendi foi valorizar o pessoal da Psicologia, da Administração. Antes eu nem sabia que eles faziam pesquisa. "Sem eles os resultados não seriam os mesmos". (P.G.N. Aluno do Curso de Eng. Elétrica). 
Nas duas primeiras semanas de reuniões na comunidade estive a ponto de desistir. Os assuntos privilegiavam o agrícola e o desenvolvimento sustentável, nada se falava de saúde. Por mais esforço que fizesse, não conseguia ver a articulação da saúde com a proposta do Núcleo Temático. A descoberta veio com a técnica da paisagem, onde fomos levados a andar pela comunidade, anotando tudo que ali existia. Ao redor das moradias e no seu interior, constatamos animais de estimação no convívio direto com as pessoas, comendo no mesmo prato restos de comida, dormindo no sofá e na cama, defecando no quintal e fuçando dejetos humanos, impactando na saúde humana e sendo pelos animais impactados. Naquele momento, tudo ficou claro para mim e passei a ver a relação da saúde com a zootecnia, com o meio ambiente, com a medicina veterinária e o desenvolvimento sustentável. Já voltei da técnica dinâmica sabendo o que a área de enfermagem poderia fazer para melhorar as condições de saúde do povo. "Para mim foi das experiências mais importantes na UNIVASF” (S.R.F. Aluna do Curso de Enfermagem).

Embora processos de aprendizagem sejam estudados no Curso de Psicologia em vários semestres, não foi fácil lidar com jovens e adultos, temática que não é objeto de aprofundamento no curso. Tivemos de estudar muito, pesquisar nos teóricos da educação, para subsidiar a nossa prática e assessorar bem os demais formadores das áreas técnicas que esperavam de nós este apoio. Mas foi algo que valeu a pena. Saímos fortalecidos desse trabalho, com conhecimentos testados na prática. "Hoje, me sinto segura para enfrentar outras situações" (J.M.S. Aluna do Curso de Psicologia).

Muitas vezes chequei a achar que não valia a pena o esforço despendido no assentamento. Na avaliação que eu fazia após cada reunião, o povo era desinteressado e não valorizava a presença da UNIVASF ali. Muitas vezes o número de membros do assentamento era quase igual ao número de alunos e de professores envolvidos com o projeto. Eu fiquei indignada no dia em que lá chegamos e eles não estavam porque preferiram participar de um torneio de futebol entre os vários assentamentos da região. Por mim, naquele dia a gente abandonava o grupo. Mas o episódio foi motivo de ampla discussão coletiva e entendi que para eles aquele evento significava o fortalecimento identitário e a demonstração de integração e pertencimento à condição de assentados. No processo aprendi coisas que nem imaginava existir. Aprendi a ser extensionista. A me comunicar com o pequeno agricultor familiar (A.P.D. Aluna do Curso Zootecnia)

Ao planejar o curso de informática para os assentados jovens e os filhos dos assentados, na perspectiva de inseri-los no mundo informatizado, não acreditava que os resultados pudessem ser tão positivos. A gente sempre tem o preconceito com os mais pobres. Mas foi surpreendente o desempenho apresentado. Logo nas primeiras aulas já sabiam conectar-se com a internet. Abriram e-mails e já faziam buscas sobre assuntos do seu interesse. Não houve evasão, os horários foram cumpridos e todos receberam o 
certificado de conclusão do curso .Foi uma boa experiência para mim"(R.P.S. Aluno do Curso de Eng. da Computação)

Como pode ser observado, apesar dos desafios enfrentados, foi um aprendizado importante para os alunos graduandos. A responsabilidade da educação é fazer com que os aprendizes desempenhem uma ação de aprender a aprender, suscitando um refazer dos conhecimentos e valores adquiridos, entendendo que a cada dia o conhecimento é compartilhado por diferentes meios, fazendo da capacidade crítica uma aliada a uma emancipação intelectual. Foi o que aconteceu, pelas falas dos participantes da experiência. Como bem afirma Moraes (2000):

Se estais preocupado em formar indivíduos autônomos, criativos, críticos, cooperativos, solidários e fraternos, maisintegradoseharmoniosos, capazesdeexplorar o universodesuas construções intelectuais, terãode optar porumparadigmaeducacionaldiferentedos modelos convencionais atuais.

Como fazer isso, quando a maioria dos educadores da universidade obteve formação dentro de uma concepção tradicional, fragmentada? Como vencer os obstáculos dos territórios do saber construídos numa visão cartesiana e pragmática? É possível desenvolver uma atitude dialógica entre atores variados, para que juntos construam aprendizagens mútuas? Como elevar a autoestima de indivíduos que historicamente foram massacrados pelo preconceito e mantidos à margem no processo de integração social? Como fazê-los acreditar que a universidade pode com eles abrir novas picadas para a construção de outro caminho?

Respostas prontas para essas indagações não existem, mas quando os atores envolvidos no processo de ensino-aprendizagem reconhecem as suas limitações, tudo pode acontecer. E assim tem ocorrido com todos os que constroem esse Núcleo Temático, até porque, o convívio com os movimentos sociais requer paciência e abertura para compreender que nem sempre o que se quer coincide com os interesses do outro, o que não significa desinteresse ou menosprezo pelas propostas apresentadas.

Os aspectos negativos observados no trabalho referem-se a dificuldades de ordem burocrática/institucional, tais como: inexistência de políticas de extensão que fortaleçam a relação universidade-comunidade e a articulação com o ensino e a pesquisa, e que superem as tradicionais práticas assistencialistas e paternalistas de ações realizadas 'para' a comunidade e não 'com' a comunidade. Ressaltamos, também, a resistência às mudanças e a dependência da vontade dos gestores no apoio logístico às atividades, transformando a extensão em 'moeda de troca', como dificuldades no processo. 
Em se tratando do grupo de assentados, observamos pouca participação nas reuniões, sobretudo naquelas que se destinavam a avaliações. As iniciativas que independiam da ação da equipe da UNIVASF ficavam inviabilizadas, o que preocupava a todos, já que a intenção era que os sujeitos da própria comunidade assumissem o processo de desenvolvimento local, definindo onde e como fazer as coisas.

\section{AVALIANDO OS RESULTADOS}

A atuação da universidade no assentamento foi encerrada no mês de dezembro de 2008. No ano de 2011, a mesma equipe de docentes e alguns alunos que participaram do projeto retornaram ao assentamento Mandacaru para avaliar os impactos resultantes das ações ali desenvolvidas com os assentados.Foram entrevistados vinte e quatro adultos do sexo masculino e dezoito do sexo feminino, além de vinte jovens entre dezoito e vinte e dois anos, perfazendo sessenta e duas pessoas.

A escolaridade da população foi elevada, considerando que todas as crianças e os jovens estão frequentando cursos de nível básico, com a expectativa de chegarem à universidade. Doze adultos estão fazendo curso de alfabetização e um deles, com mais de sessenta anos, afirmou que está determinado a fazer um curso superior de agronomia. O número de associados na organização coletiva foi ampliado, arcando a grande maioria (76,6\%), com o pagamento da mensalidade que mantém a instituição.

Foi observada a preocupação com temas da atualidade veiculados pela mídia, como política, tecnologias de convivência com o semiárido e desenvolvimento territorial. O associativismo hoje é considerado um mecanismo importante de barganha e articulação política, além de oportunizar a todos distribuição igualitária na aquisição de financiamentos.

A renda com a venda de verduras e legumes da horta agroecológica; com a fábrica de vassoura feita com garrafas PET; com a criação de pequenos animais, bem como, oriunda dos pequenos comércios de bares e mercadinhos, além da prestação de serviços de salão de beleza, costura, bordados, barbearia e confecção de doces, bolos, sequilhos e artesanato, tem contribuído para a aquisição de bens de consumo, sendo a motocicleta o bem prioritário na lista dos desejos, por facilitar a locomoção para a cidade. As aposentadorias para os mais idosos e os programas sociais do governo federal também são responsáveis pela melhoria da qualidade de vida das famílias. 
Nas atividades agropastoris, constatou-se a prática da fenação, silagem, sal proteinado, amoniação e manejo dos solos e do pequeno rebanho caprino. A criação de galinha caipira e a produção de ovos para comercialização têm ampliado a renda das mulheres.

Outra atividade muito reconhecida na comunidade, especialmente para os dirigentes da associação, é a elaboração de projetos para busca de financiamentos junto ao PRONAF- Programa Nacional da Agricultura Familiar e os bancos oficiais. Hoje, a associação não paga mais por esse serviço, sendo que este aprendizado desenvolvido com a UNIVASF foi um dos mais importantes. Afirmam também os assentados que os cursos de administração lhes ensinaram a usar melhor o tempo.

A capacitação em inclusão digital ministrada para os jovens do assentamento foi muito importante na avaliação de todos, por ter facilitado o ingresso no mercado de trabalho. Como os lotes são muito pequenos, necessário se faz que os membros da família busquem alternativas de sobrevivência como assalariados. O computador é o segundo bem mais desejado e já são quinze pessoas a possuí-lo, sendo os usuários desse equipamento, em grande parte (40\%) jovens.

O projeto executado pela UNIVASF para formar agentes de desenvolvimento na perspectiva de melhorar a qualidade de vida da população impactou positivamente, constatando-se melhorias na alimentação, na engenharia habitacional e na organização para o trabalho.

O trabalho educativo de formação foi fundamental para a promoção do desenvolvimento dos assentados, consolidando o assentamento como espaço de coletividade e de união de forças em prol da gestão participativa, sem violar a cultura local. Entre a população do campo, como afirma Lacki (2002:4),

\begin{abstract}
"a ineficiência do fator de produção mais abundante que é a mão de obra, incide negativamente na produtividade dos demais fatores que geralmente são escassos, como a terra, os animais, os insumos, as máquinas, apresentando-se a educação como o a ferramenta com maior potencial para empoderar as famílias, por contemplar valores como cidadania, autonomia, solidariedade, democracia e respeito ao meio ambiente".
\end{abstract}

Observa-se ainda que a caatinga passou a ser valorizada em sua riqueza e diversidade, ressaltando a importância de preservar os recursos naturais, evitando a queimada, o desmatamento e a caça predatória, num ecossistema já bastante comprometido.

Na região semiárida do nordeste, a agricultura, segundo estudos da FAO (1999:77) e do Banco Mundial (2000:157), por muito 
tempo ainda será a principal fonte de ocupação e renda, embora novas formas de utilização do espaço rural estejam acontecendo. $\mathrm{Na}$ mesma compreensão, Abromovay (1998:33) informa que grande parte dos agricultores pobres só poderão se manter tornando a produção pluriativa, ou seja, explorando as várias dimensões da propriedade, daí a importância de se trabalhar a educação, a fim de que possam transformar as potencialidades em oportunidades de trabalho e renda.

Como ponto negativo da experiência, foi colocado o tempo de permanência da equipe da UNIVASF no assentamento como insuficiente para a consolidação do trabalho de educação. Os entrevistados alegaram que foi muita informação em um curto período, impossibilitando que as mesmas fossem bem incorporadas. Na avaliação, pelo menos mais um ano de acompanhamento semanal seria necessário para que as práticas fossem sedimentadas e os ajustes feitos. A fala de G.R.S. 58 anos, analfabeta é bem esclarecedora desse sentimento: "Quase nenhum de nós já tinha pisado numa sala de aula. Ai chegam vocês pra ensina em dois ano o que o povo da cidade gasta mais de dez pra aprender. Ai só se fosse milagre, nós pegá tudo".Faltou da parte da academia um diálogo mais efetivo com os aprendentes e maior sensibilidade para perceber em tempo real essas dificuldades. Sobre o assunto, vale tomar como referência o educador Paulo Freire (1999:57):

Existir é um conceito dinâmico que implica uma dialogação eterna do homem com o homem. Do homem com o mundo, do homem com o seu Criador. É essa dialogação do homem sobre o mundo e com o mundo mesmo, sobre os desafios e problemas que o faz diferente, o faz histórico. Quando as condições existentes não favorecem tais atitudes, o homem passa a entender o seu destino como predestinação, acatando-o como desígnio de Deus.

A dinamicidade que caracteriza a extensão universitária é o que permite ao ensino e à pesquisa se revitalizarem a partir das respostas por ela trazidas, relacionadas aos anseios e às demandas da sociedade. 


\section{REFERÊNCIAS BIBLIOGRÁFICAS}

ABROMOVAY, R. Paradigmas do capitalismo agrário em questão. Campinas: Hucitec, 1998.

Desenvolvimento rural territorial e capital social. In: SABOURIN, E. et al. Planejamento e desenvolvimento dos territórios rurais - conceitos, controvérsias e experiências. Brasília: EMBRAPA Informações Técnicas, 2002.

ALMEIDA FILHO, N. Transdisciplinaridade e Saúde Coletiva. Ciência \& Saúde Coletiva, v.2, n.1-2, 1997.

BANCO MUNDIAL. Le Développement au seuil du XX éme siécle. Paris: ESKA, 2000.

FAO. Anuário FAO. Roma: Produção, 1999.

FREIRE, P. Educação como prática de liberdade. Rio de Janeiro: Paz e Terra, 2002.

KIELING, S.R.F. O construtivismo e a educação. Porto Alegre: Mediação, 2001.

LACKI, P. Como enfrentar a crise da agricultura: lamentando os problemas insolúveis ou resolvendo os problemas solucionáveis? Roma: Papers da FAO, 2002.

MANACORDA, M.A. Marx e a pedagogia moderna. São Paulo: Cortez. 1991.

MORAIS, R. (Org.). Sala de aula: que espaço é esse? São Paulo: Papirus, 2002.

OLIVEIRA, L.M.S.R.; OLIVEIRA, L.S. Reflexões sobre os agentes de desenvolvimento e a sua relação com a sustentabilidade do Alto Sertão Piauí-Pernanbuco: uma abordagem teórico-metodológica. In: MENEZES, A.H.N.; CÂNDIDO, R.A.; OLIVEIRA, L.M.S.R. et al. (Eds.) Formação de Agentes de Desenvolvimento Sustentável: diálogos entre o fazer técnico e o saber humanista. Juazeiro: Editora e Gráfica Franciscana, 2007.

SAVIANE, D. Educação: do censo comum à consciência filosófica. São Paulo: Autores Associados e Cortez, 1998.

ZAPATA, T. Capacitação, associativismo e desenvolvimento social. Recife: Projeto Banco do Nordeste / PNUD. Série de Cadernos Técnicos, 2000. 
58 Revista ELO - Diálogos em Extensão

Volume 01, número 01 - dezembro de 2012 